\title{
Higher numbers of circulating endothelial progenitor cells in stroke patients with intracranial arterial stenosis
}

\author{
Zhizhong Liu', Xiurong Ding ${ }^{2}$, Fang Fang ${ }^{1}$, Ruimin Wang ${ }^{1}$, Yan Chen ${ }^{1}$, Yuetao Ma ${ }^{3}$, Guojun Zhang ${ }^{1}$ \\ and Xixiong Kang ${ }^{1 *}$
}

\begin{abstract}
Background: Bone marrow-derived endothelial stem cells participate in vascular repairs. Numbers of circulating endothelial progenitor cells (cEPCs) are associated with atherosclerosis. Fibrinogen plays a key role in atherosclerosis. Objective was to assess if cEPC counts were associated with atherosclerotic intracranial artery stenosis (IAS).

Methods: Three hundred subjects (108 patients with stroke and IAS (IAS), 120 control patients with stroke without IAS (CP), and 72 healthy controls $(\mathrm{HC})$ ) were retrospectively analyzed. CEPCs were identified and counted by flow cytometry using CD34, CD133 and KDR. Plasma fibrinogen was measured by immunoturbidimetry. CEPC counts were compared between the three groups.

Results: $C E P C$ numbers were significantly higher in IAS $(0.059 \pm 0.031 \%)$ than in CP $(0.026 \pm 0.012 \%)(P<0.001)$ and $H C(0.021 \pm 0.011 \%)(P<0.001)$, but without difference between $C P$ and $H C(P=0.401)$. Multiple logistic regression analysis showed that CEPC levels (OR 3.31, 95\%Cl 1.26-8.87, $P=0.025$; IAS vs. CP) were independent markers of IAS after adjustment for hypertension, diabetes and smoking. No significant correlation between CEPC counts and plasma fibrinogen levels was observed $(P>0.05)$.

Conclusion: CEPC numbers were associated with degrees of IAS. This measurement may be useful for non-invasive evaluation of atherosclerotic IAS.
\end{abstract}

Keywords: Intracranial artery stenosis, Atherosclerosis, Circulating endothelial progenitor cells, Fibrinogen

\section{Background}

Intracranial arterial stenosis (IAS) is an important cause of stroke. The number of intracranial symptomatic vessels and their stenosis degree is associated with a higher risk of stroke recurrence and other major ischemic events [1-4]. However, the mechanisms for atherosclerosis initiation and progression in intracranial large arteries are still ill understood. First, intracranial atherosclerosis may be characterized by multiple stenoses of cerebral large arteries, which may result in chronic brain hypoperfusion, responsible for an enhanced angiogenic response [5]. Secondly, endothelial repair may be crucial for atherosclerosis progression in intracranial large arteries [6]. In addition, bone

\footnotetext{
*Correspondence: KangXixiongmedsci@163.com

${ }^{1}$ The Centre for Laboratory Diagnosis, Beijing Tiantan Hospital, Capital Medical University, Beijing 100050, China

Full list of author information is available at the end of the article
}

marrow-derived endothelial stem cells can differentiate into mature vascular endothelial cells and participate in vascular repair [7].

Many factors, including proinflammatory interleukin (IL)-8 [8] and chemokine monocyte chemoattractant protein-1 (MCP-1) [9], are important for endothelial progenitor cells (EPCs) mobilization. Furthermore, even if their exact role is not yet completely understood, circulating EPCs (cEPCs) are involved in vascular pathologies [10-13]. Elevated cEPC levels have been associated with atherosclerotic diseases, but the results are conflicting [14-20]. Serum IL-8 and MCP-1 levels are elevated in pathological conditions, along with elevated numbers of cEPCs [12,18,21-23]. Fibrinogen exposure can result in up-regulation of expression and secretion of MCP-1 and IL-8 in endothelial [24] and dendritic cells [25]. Fibrinogen plays a key role in the development of atherosclerosis [26]. 
We hypothesized that there might be a potential association between plasma fibrinogen levels, cEPCs and IAS. This present study explored the association between cEPC numbers and IAS, and if there was a correlation between EPC and fibrinogen levels. cEPCs might be a disease marker in IAS, and may also be a treatment target in IAS.

\section{Methods}

\section{Patient demographics and exclusion criteria}

This study was approved by the Ethics Committee of the Beijing Tiantan Hospital Affiliated to the Capital Medical University, China (approval \#KYLW2013-004-01), and individual informed consent was waived. A cohort of 108 patients with symptomatic IAS, 120 control patients without IAS (CP) and 72 healthy controls (HC) from September 2011 to July 2012 were retrospectively analyzed. IAS and CP patients were selected from patients with a firstever ischemic stroke in the neurology department of the Beijng Tiantan Hospital. Intra- and extracranial cerebral large arteries were evaluated by trans-cranial Doppler (TCD) in all subjects. IAS was reconfirmed by digital subtraction angiography (DSA). Exclusion criteria were: 1) modified Rankin Scale score > 2; 2) emboligenic cardiopathy; 3) cancer diagnosis; 4) chronic inflammatory disease; or 5) non-atherosclerotic intracranial stenosis, such as Sneddon syndrome, Moya-Moya disease, postradiotherapy angiopathy, and vasculitis.

\section{Image acquisition}

TCD was performed using a MultiDop-X/TCD (Compumedics DWL, Singen, Germany), with a hand-held transducer in a range-gated, pulsed-wave mode at a frequency of $2 \mathrm{Mhz}$. IAS was diagnosed according to validated criteria [27]. Cervical intracranial artery (ICA) atherosclerosis was regarded as any ICAs showing a stenosis $\geq 50 \%$.

Intracranial stenosis was reconfirmed by DSA (Innova 3100IQ, GE Healthcare, Waukesha, WI, USA,) and was defined as a focal stenosis $\geq 50 \%$ in luminal reduction affecting the main cerebral large arteries. Stenosis was classified as severe $(\geq 70 \%)$ or non-severe $(<70 \%)$, based on the symptomatic narrowed artery [1].

\section{Flow cytometry}

Peripheral blood $(2 \mathrm{~mL})$ was collected in tubes containing $\mathrm{K}_{2}$-EDTA on the $7^{\text {th }}$ day after acute onset and was processed within 1 hour of collection. Peripheral blood mononuclear cells (PBMCs) were isolated by density gradient centrifugation using Ficoll-Hypaque (Amersham, GE Healthcare, Waukesha, WI, USA), washed with PBS, and counted for recovery and viability using Trypan Blue. Since EPCs are characterized by the co-expression of CD34, CD133 and KDR [28,29], we determined the proportion of cEPCs in PBMCs by flow cytometry using a triple staining with fluorescein-conjugated monoclonal antibodies against these markers. Briefly, PBMCs $\left(1 \times 10^{6}\right)$ were incubated with CD34-PerCP-Cy5.5 (Becton Dickinson, Franklin Lake, NJ, USA), CD133-PE (eBioscience, San Diego, CA, USA), and KDR-Alexa Flour647 (Becton Dickinson, USA) for $25 \mathrm{~min}$ at $4^{\circ} \mathrm{C}$ in a dark room. Non-specific binding was determined by staining an aliquot of cells with fluorescein-conjugated IgG1 and IgG2a isotype controls (Becton Dickinson, Franklin Lake, NJ, USA). After washing once with PBS, cells were fixed with 1\% paraformaldehyde and analyzed using a FACS Calibur flow cytometer (Becton Dickinson, USA). We gated CD34+ peripheral blood cells in the mononuclear cell fraction, followed by the examination of the resulting subpopulation for expression of KDR, CD133 or both. The frequency of peripheral blood cells positive for these markers was determined by a 2-dimensional side-scatter fluorescence dot-plot analysis, after appropriate gating. A minimum of 50,000 events was acquired for each sample. Data were analyzed using the embedded Cellquest software. EPC numbers were expressed as the proportion of total PBMCs.

\section{Plasma fibrinogen levels}

On the $7^{\text {th }}$ day after acute onset, peripheral blood $(3 \mathrm{~mL})$ was collected in tubes containing sodium citrate to measure plasma fibrinogen levels, using a CA5000 Coagulation Analyzer (Sysmex, Kobe, Japan).

\section{Statistical analysis}

Inter-groups differences were assessed using the $X^{2}$, Fisher's exact tests, Student's $t$-test or one-way ANOVA with post hoc analysis. Pearson correlation analysis was used to analyze the relationship between plasma fibrinogen levels and cEPC numbers. A multiple logistic regression model was used to identify independent IAS markers (variables with a $P$-value $<0.05$ in univariate testing were included); adjustment for age, gender, and vascular risk factors was also performed. Results are expressed as adjusted odds ratios (OR) and corresponding 95\% confidence intervals (CI). $P<0.05$ was considered to be statistically significant. All analyses were performed using SPSS 13.0 (SPSS Inc., Chicago, IL, USA).

\section{Results}

\section{Patients' characteristics}

Table 1 presents subjects' demographics and risk factor characteristics. The proportion of patients with hypertension, diabetes and tobacco use were higher in the IAS group (all $P<0.001$ ). A total of 206 stenoses in 108 IAS patients were identified.

\section{Endothelial progenitor cells}

The proportions of CD34+ cells were $0.293 \pm 0.182 \%$ in $\mathrm{HC}, 0.364 \pm 0.201 \%$ in $\mathrm{CP}$, and $0.553 \pm 0.311 \%$ in IAS 
Table 1 Patients' demographic and risk factor characteristics

\begin{tabular}{|c|c|c|c|c|c|c|}
\hline & $\mathrm{HC}(n=72)$ & $C P(n=120)$ & IAS $(n=108)$ & $\mathbf{P}^{\Delta}$ & $\mathrm{P}^{\#}$ & $P^{*}$ \\
\hline Age, mean $\pm S D$ & $56.0 \pm 10.2$ & $56.9 \pm 7.6$ & $61.5 \pm 12.1$ & 0.652 & 0.132 & 0.281 \\
\hline Gender (female), n (\%) & $28(38.9)$ & $48(40.0)$ & $48(44.4)$ & 0.879 & 0.460 & 0.497 \\
\hline $\mathrm{BMI}, \mathrm{Kg} / \mathrm{m} 2$ & $24.2 \pm 4.2$ & $26.1 \pm 8.6$ & $26.9 \pm 8.9$ & 0.035 & 0.031 & 0.756 \\
\hline $\mathrm{sBP}, \mathrm{mmHg}$ & $123.2 \pm 17.7$ & $134.1 \pm 16.54$ & $138.1 \pm 18.72$ & 0.065 & 0.036 & 0.452 \\
\hline $\mathrm{dBP}, \mathrm{mmHg}$ & $81.6 \pm 10.1$ & $83.52 \pm 12.05$ & $85.6 \pm 10.1$ & 0.396 & 0.041 & 0.462 \\
\hline $\mathrm{TG}, \mathrm{mmol} / \mathrm{l}$ & $1.325 \pm 0.35$ & $1.446 \pm 0.77$ & $1.504 \pm 0.83$ & 0.689 & 0.478 & 0.837 \\
\hline $\mathrm{TC}, \mathrm{mmol} / \mathrm{l}$ & $3.935 \pm 0.93$ & $4.078 \pm 0.68$ & $4.697 \pm 0.85$ & 0.696 & 0.019 & 0.089 \\
\hline $\mathrm{HDL}, \mathrm{mmol} / \mathrm{l}$ & $1.198 \pm 0.26$ & $1.05 \pm 0.16$ & $0.955 \pm 0.15$ & 0.099 & 0.003 & 0.297 \\
\hline $\mathrm{LDL}, \mathrm{mmol} / \mathrm{I}$ & $2.43 \pm 0.81$ & $2.626 \pm 0.55$ & $2.624 \pm 0.78$ & 0.623 & 0.601 & 0.991 \\
\hline Glu, mmol/l & $5.75 \pm 1.06$ & $6.059 \pm 3.32$ & $5.58 \pm 0.97$ & 0.745 & 0.748 & 0.555 \\
\hline CRP, mg/l & $0.65(0.31-1.37)$ & $1.55(0.65-2.71)$ & $2.75(1.2-3.25)$ & 0.021 & $<0.001$ & 0.012 \\
\hline Hypertension, n (\%) & 0 & $30(25.0)$ & $84(77.8)$ & - & - & $<0.001$ \\
\hline \multicolumn{7}{|l|}{ cEPCs (\%) } \\
\hline CD34+ & $0.293 \pm 0.182$ & $0.364 \pm 0.201$ & $0.553 \pm 0.311$ & 0.028 & 0.009 & 0.019 \\
\hline CD34+/CD133+ & $0.098 \pm 0.032$ & $0.113 \pm 0.064$ & $0.246 \pm 0.142$ & 0.382 & $<0.001$ & $<0.001$ \\
\hline CD34+/CD133+/KDR+ & $0.021 \pm 0.011$ & $0.026 \pm 0.012$ & $0.059 \pm 0.031$ & 0.401 & $<0.001$ & $<0.001$ \\
\hline Diabetes, n (\%) & 0 & $6(5.0)$ & $24(22.2)$ & - & - & $<0.001$ \\
\hline Hyperlipidemia, n (\%) & 0 & $18(15.0)$ & $24(22.2)$ & - & - & 0.160 \\
\hline CAD, n (\%) & 0 & $12(10.0)$ & $18(16.7)$ & - & - & 0.137 \\
\hline Smoking, n (\%) & 0 & $48(40.0)$ & $78(72.2)$ & - & - & $<0.001$ \\
\hline Drug treatment & & & & - & - & \\
\hline Statin, n (\%) & $4(5)$ & $31(26)$ & $35(32)$ & - & - & 0.316 \\
\hline ACE inhibitor, n (\%) & - & $20(17)$ & $31(29)$ & - & - & 0.029 \\
\hline Angiotensin II receptor blocker, n (\%) & - & $3(2)$ & $2(2)$ & - & - & 0.739 \\
\hline Beta blocker, n (\%) & - & $10(8)$ & $13(12)$ & - & - & 0.345 \\
\hline Calcium antagonist, n (\%) & - & $19(16)$ & $34(32)$ & - & - & 0.005 \\
\hline
\end{tabular}

$\mathrm{P}^{\Delta}$ : $C P$ vs. HC $\mathrm{P}^{\#}$ : IAS vs. HC $P^{*}$ : IAS vs. CP.

SBP: systolic blood pressure; dBP: diastolic blood pressure.

$\mathrm{HC}$, healthy controls; CP, control patients; IAS, patients with intracranial artery stenosis; CAD: coronary artery disease.

patients (all $\mathrm{P}<0.05)$. The proportions of CD34+/CD133+ cells were $0.098 \pm 0.032 \%$ in $\mathrm{HC}, 0.113 \pm 0.064 \%$ in $\mathrm{CP}$, and $0.246 \pm 0.142 \%$ in IAS patients $(\mathrm{P}<0.001$ for IAS vs. $\mathrm{CP}$ and $\mathrm{HC} ; \mathrm{P}=0.382$ for $\mathrm{CP}$ vs. $\mathrm{HC}$ ) (Table 1 ). The proportions of $\mathrm{CD} 34+/ \mathrm{CD} 133+/ \mathrm{KDR}+\mathrm{cEPCs}$ among total PBMCs were $0.021 \pm 0.011 \%$ in $\mathrm{HC}, 0.026 \pm 0.012 \%$ in $\mathrm{CP}$, and $0.059 \pm 0.031 \%$ in IAS patients (Figure 1A). The number of $\mathrm{CD} 34+/ \mathrm{CD} 133+/ \mathrm{KDR}+\mathrm{cEPCs}$ was significantly higher in patients with IAS than in $\mathrm{CP}$ and $\mathrm{HC}$ (all $\mathrm{P}<$ 0.001 ), but no significant difference was observed in cEPCs between CP and HC $(P=0.401)$.

Multiple logistic regression showed that the numbers of cEPCs (OR 3.31, 95\%CI 1.26-8.87, $p=0.025$; IAS vs. CP) were an independent IAS marker after adjustment for hypertension, diabetes, smoking and CRP levels (Table 2).

In $\mathrm{HC}$, numbers of cEPCs were not different between subjects $<60(\mathrm{n}=39)$ and $\geq 60$ years old $(0.018 \pm 0.009 \% v s$. $0.022 \pm 0.011 \%, p=0.476)$. However, cEPCs numbers in
IAS patients $<60(n=60)$ was significantly higher than in patients $\geq 60$ years old $(0.077 \pm 0.035 \%$ vs. $0.045 \pm 0.016 \%$ $P=0.019$ ) (Figure 1B). Among subjects $\geq 60$ years old, cEPCs numbers in the IAS group were 2.1 times higher than in HC. Among subjects $<60$ years old, cEPCs numbers in the IAS group were 4.3 times higher than in $\mathrm{HC}$. There was no difference between male and female patients $(0.063 \pm 0.039$ vs. $0.055 \pm 0.032 \%, P=0.198)$. Diabetic patients had significantly less EPCs than non-diabetics $(0.043 \pm 0.019$ vs. $0.065 \pm 0.042 \%, P=0.024)$ (Figure $1 C)$.

\section{Association between CEPC numbers and clinical characteristics in IAS patients}

As shown in Table 3, cEPC numbers were significantly higher in patients with $\geq 70 \%$ stenosis than in those with $<70 \%$ stenosis $(0.091 \pm 0.035 \%$ vs. $0.052 \pm 0.022 \%$, $P=0.012)$. There was no significant difference in cEPCs between 1,2 and $>2$ stenosed artery $(P=0.578)$. 


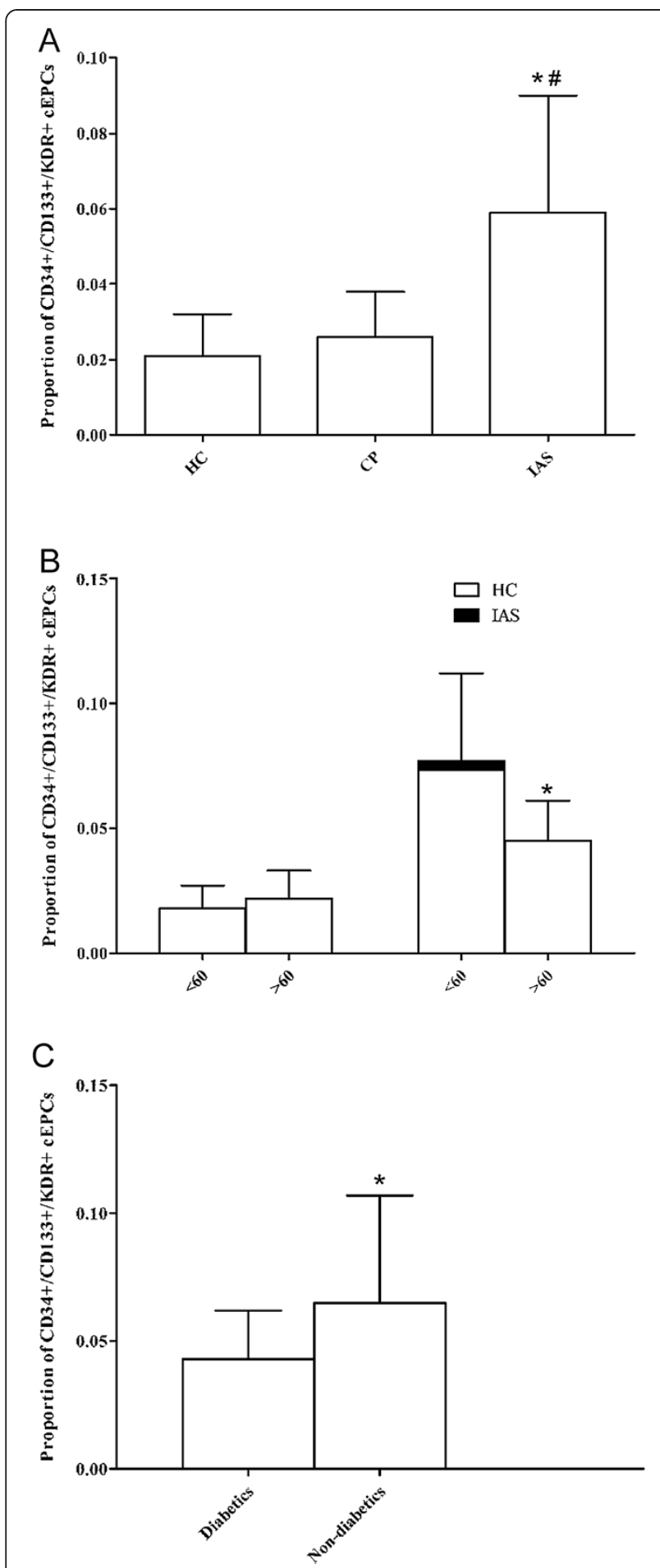

Figure 1 cEPCs proportions across different groups. (A) CEPC levels in the peripheral blood of HC, CP and IAS $\left({ }^{*} P<0.01\right.$, IAS vS. $H C$; $\# P<0.01$, IAS vs. CP). Rresults are presented as mean \pm SD. (B) Differences in CEPC levels in the peripheral blood of HC and IAS according to age ( ${ }^{*} P<0.05,<60$ vs. $\geq 60$ years old in IAS patients). Results are presented as mean \pm SD. (C) Differences in cEPCs levels of IAS according to the diabetes status ( ${ }^{*} P<0.05$ vs. diabetics).
Table 2 Multivariate model of characteristics hypothesized to be associated with IAS (IAS vs. CP)

\begin{tabular}{lccc}
\hline Characteristic & Odds ratio & $\mathbf{9 5 \% ~ C l}$ & $\boldsymbol{P}$ \\
\hline Hypertension (yes vs. no) & 1.38 & $0.97-2.59$ & 0.045 \\
Diabetes (yes vs. no) & 1.73 & $1.15-2.89$ & 0.017 \\
Tobacco use (yes vs. no) & 2.23 & $1.02-5.15$ & 0.038 \\
CRP (per 1 mg/l increase) & 2.25 & $1.22-3.96$ & 0.029 \\
CEPCs counts (per 1\% increase) & 3.31 & $1.26-8.87$ & 0.025 \\
\hline
\end{tabular}

\section{Association between CEPC numbers and plasma} fibrinogen levels

Compared with $\mathrm{HC}, \mathrm{CP}$ and IAS patients showed higher plasma fibrinogen levels $(3.09 \pm 0.51 \mathrm{mg} / \mathrm{L}$ vs. $3.62 \pm 0.52$ and $3.84 \pm 0.62 \mathrm{mg} / \mathrm{L}$, respectively) (Figure 2). No significant correlation was detected between cEPC numbers and plasma fibrinogen levels in the three groups (HC: $r=0.29$, $P=0.21$; CP: $r=0.19, P=0.54$; IAS: $r=0.23, P=0.32$ ).

\section{Discussion}

Our study demonstrated that IAS patients had an increased mobilization of cEPCs in peripheral circulation. Moreover, cEPC levels were higher in patients with higher stenosis $(\geq 70 \%)$. However, we did not observe any correlation between cEPC and fibrinogen levels. Nevertheless, cEPC counts could be used to assess the extent of IAS.

The association between the number of cEPCs and clinical manifestations of atherosclerosis has been previously reported. Morishita et al. [12] observed that the number of cEPCs was a marker of severity of peripheral artery diseases. In addition, Rafat et al. [21] showed that the number of EPCs was significantly higher in patients with atherosclerotic cerebral vascular disease compared with healthy controls. Chu et al. [22] showed that cEPC counts were associated with known markers of vasculopathy (HbA1c and homocysteine) in acute stroke patients. Pelliccia et al. [18] showed that $\mathrm{CEPC}$ numbers were associated with prognosis in patients with percutaneous coronary intervention (PCI)-treated stable angina, and that PCI-treated stable angina patients with restenosis had higher $\mathrm{CEPC}$ numbers

Table 3 cEPC levels according to stenosis degree and the number of symptomatic vessels in IAS patients

\begin{tabular}{lccc}
\hline & $\begin{array}{c}\text { Number of } \\
\text { patients }\end{array}$ & cEPCs(\%) & $\boldsymbol{P}$ \\
\hline $\begin{array}{l}\text { Stenosis } \\
<70 \%\end{array}$ & 48 & $0.052 \pm 0.022$ & 0.012 \\
$\geq 70 \%$ & 60 & $0.091 \pm 0.035$ & \\
Number of intracranial & & & 0.578 \\
symptomatic arteries & & & \\
1 & 30 & $0.065 \pm 0.024$ & \\
2 & 26 & $0.058 \pm 0.033$ & \\
$>2$ & 52 & $0.067 \pm 0.044$ & \\
\hline
\end{tabular}




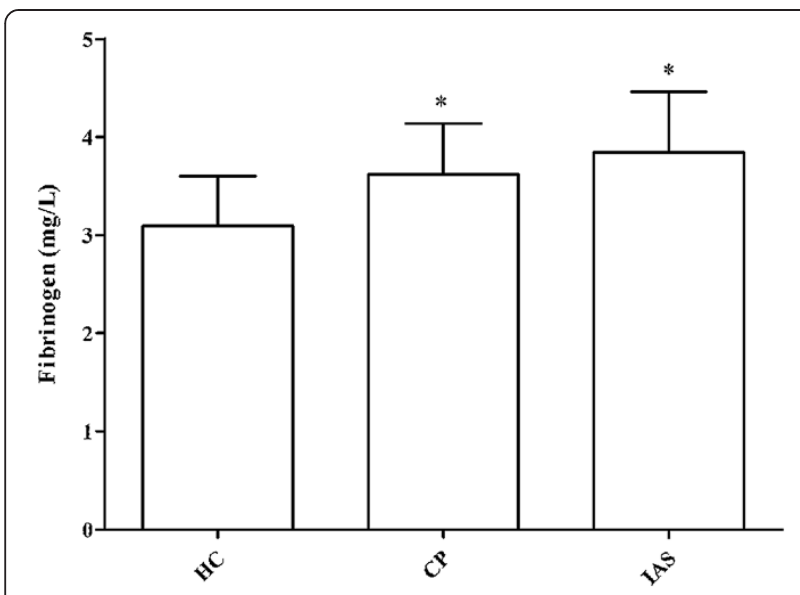

Figure 2 Differences in fibrinogen levels between the three groups $\left({ }^{*} P<0.05\right.$ vs. healthy controls). Results are presented as mean $\pm \mathrm{SD}$.

[23]. On the other hand, Yoshihara et al. [30] observed no differences in circulating CD34+ cells in patients with major cerebral artery occlusion (or sever stenosis), and Sobrino et al. [31] showed that elevated cEPC numbers indicated an improved prognosis in stroke patients. This might be explained by the fact that CD34 is also present on mature endothelial cells and monocytes, and cannot be used alone to characterize bone marrow-derived immature cells. Although the exact phenotype of cEPCs is still controversial, the concomitant presence of CD34, CD133 and KDR seems to be well-supported [28,29], and we used this profile in the present study. Our results suggest that cEPCs, defined as CD34+/CD133+/KDR + cells, may indicate a disorderly growth of vascular endothelium in different intracranial lesions. Thus, these cells may be a useful marker for IAS. However, the association between cEPCs and markers of atherosclerosis remains controversial, as shown by previous studies [12,18,21-23], and the results from the present study about the lack of association between cEPC and fibrinogen levels.

However, these previous studies did not discriminate between intracranial or extracranial artery stenosis. One of our previous studies suggested that there were obvious differences between atherosclerosis lesions in intra- and extracranial cerebral large arteries [32]. Thus, ideally, intra- and extracranial atherosclerosis should be studied separately. In the present study, we observed that cEPC levels in patients with IAS were significantly higher than in HC. Moreover, cEPC numbers in IAS were significantly higher compared with stroke patients without IAS. These results indicate that abnormal EPC mobilization may play a role in the development and presence of IAS. Indeed, under normal circumstances, cEPCs participate in the formation and repair of vascular endothelial cells [7]. However, pathological conditions increasing EPCs activity might lead to excessive angiogenesis and artery narrowing. Ischemia and hypoperfusion induce endogenous VEGF production, which is an important factor for EPC mobilization [33]. However, ischemia symptoms are similar between patients with or without IAS. Therefore, we suppose that ischemia is not the only reason for higher cEPC numbers observed in patients with IAS. Our results also showed that CEPC numbers were not associated with the number of stenotic intracranial arteries, but with the degree of IAS, suggesting that stenosis degree and number of symptomatic intracranial arteries may be determined by different factors.

Increasing age has been shown to be associated with reduced cEPC levels in patients with coronary artery disease (CAD) [14]. In this present study, no difference was observed in cEPC levels between age groups $(<60$ and $\geq 60$ years old) in HC. However, we observed that cEPC numbers were significantly higher in IAS patients $<60$ years old compared with $\geq 60$. These results indicated that higher cEPC numbers might play a more important role in atherosclerosis progression in younger patients.

Many factors, including growth factors, proinflammatory cytokines, chemokines, hormones and lipid-lowering and antidiabetic drugs, have been regarded as important factors involved in EPC mobilization [34]. Fibrinogen is an inflammatory marker and is closely related with atherosclerosis [24-26]. To the best of our knowledge, no study focused on the association between fibrinogen levels and cEPCs mobilization. Our study showed that serum fibrinogen levels were higher in IAS patients and CP compared with $\mathrm{HC}$, but that there was no difference between IAS and $\mathrm{CP}$, suggesting that fibrinogen might not be a key factor stimulating cEPCs mobilization specifically in IAS. This was further supported by the lack of correlation between cEPC numbers and plasma fibrinogen levels in IAS and $\mathrm{CP}$.

Studies on the relationship between cEPC numbers and coronary artery stenosis (CAS) are conflicting. It was reported that cEPC numbers were decreased in CAD with significant CAS [15]. However, Guven et al. [16] observed that $\mathrm{CEPC}$ numbers were higher in patients with significant CAS compared with patients without significant CAS. This might be due to the criteria used to identify specific angiogenic cell subpopulations and to evaluate CAD. These results in combination with our study suggested that the difference in the definition of cEPCs might greatly influence the correlation of cEPCs with the specific diseases such as IAS and CAS.

The present study has some limitations. First, even if we used a widely recognized method to identify cEPCs, there is a lack of standardization for this measurement, which could affect the results. Second, we cannot rule out the possibility that the elevation in CD34+ and CD133+ cells 
was caused by tissue ischemia inducing increased VEGF levels and peripheral blood cells mobilization. Third, it is possible that drugs taken by the patients might affect the proportions of EPCs. Fourth, we did not measure inflammation and stress markers in stroke patients, only CRP. Lastly, our sample size limits the application of our data in current clinical practice. Therefore, our results need to be confirmed in large-scale trials. Despite these limitations, our results revealed that higher $\mathrm{CEPC}$ numbers were closely associated with IAS.

\section{Conclusion}

Our study demonstrated that higher cEPC numbers were involved in IAS. It also indicated that fibrinogen may not be the main mediator for cEPCs mobilization in IAS. More studies are required to assess the key factors involved in cEPCs mobilization in IAS, and to evaluate the effects of IAS treatments on cEPC numbers.

\section{Abbreviations \\ ACA: Anterior cerebral artery; BA: Basilar artery; CAD: Coronary artery disease; CAS: Coronary artery stenosis; CEPCs: Circulating endothelial progenitor cells; Cl: Confidence interval; CP: Control patients; DSA: Digital subtraction angiography; EPC: Endothelial progenitor cells; HC: Healthy controls; IAS: Intracranial artery stenosis; ICA: Internal carotid artery; IL: Interleukin; MCA: Middle cerebral artery; MCP-1: Monocyte chemoattractant protein-1; OR: Odds ratio; PBMCs: Peripheral blood mononuclear cells; PCA: Posterior cerebral artery; PCl: Percutaneous coronary intervention; SD: Standard deviation; TCD: Transcranial doppler; VA: Vertebral artery.}

\section{Competing interest}

The authors declare that they have no competing interest.

\section{Authors' contributions}

ZL carried out the flow cytometry analysis, and drafted the manuscript. XD participated in the design of the study and performed the statistical analysis. FF and YC carried out the biochemical analysis. RW participated in flow cytometry analysis and drafting of the manuscript. YM verified and evaluated the clinical data of the patients with cerebral artery stenosis. GZ participated in the coordination of the study and drafting of the manuscript. XK conceived of the study, and participated in its design and coordination. All authors read and approved the final manuscript.

\section{Acknowledgments}

This work was funded by a grant from the 863 National Program from the Ministry of Science and Technology of the People's Republic of China (\#2006AA020706).

\section{Author details}

${ }^{1}$ The Centre for Laboratory Diagnosis, Beijing Tiantan Hospital, Capital Medical University, Beijing 100050, China. ${ }^{2}$ Clinical Laboratory Centre, Beijing Friendship Hospital, Capital Medical University, Beijing 100050, China. ${ }^{3}$ Department of Neurology, Beijing Tiantan Hospital, Capital Medical University, Beijing 100050, China.

\section{Received: 20 June 2013 Accepted: 28 October 2013}

Published: 5 November 2013

\section{References}

1. Kasner SE, Chimowitz MI, Lynn MJ, Howlett-Smith H, Stern BJ, Hertzberg VS, Frankel MR, Levine SR, Chaturvedi S, Benesch CG, et al: Predictors of ischemic stroke in the territory of a symptomatic intracranial arterial stenosis. Circulation 2006, 113(4):555-563.

2. Mazighi M, Tanasescu R, Ducrocq X, Vicaut E, Bracard S, Houdart E, Woimant $F$ : Prospective study of symptomatic atherothrombotic intracranial stenoses: the GESICA study. Neurology 2006, 66(8):1187-1191.
3. Wong KS, Li H: Long-term mortality and recurrent stroke risk among Chinese stroke patients with predominant intracranial atherosclerosis. Stroke 2003, 34(10):2361-2366.

4. Wong KS, Li H, Chan YL, Ahuja A, Lam WW, Wong A, Kay R: Use of transcranial Doppler ultrasound to predict outcome in patients with intracranial large-artery occlusive disease. Stroke 2000, 31(11):2641-2647.

5. Arenillas JF, Alvarez-Sabin J: Basic mechanisms in intracranial large-artery atherosclerosis: advances and challenges. Cerebrovasc Dis 2005, 20(Suppl 2):75-83.

6. Hutter R, Sauter BV, Reis ED, Roque M, Vorchheimer D, Carrick FE, Fallon JT, Fuster $V$, Badimon JJ: Decreased reendothelialization and increased neointima formation with endostatin overexpression in a mouse model of arterial injury. Circulation 2003, 107(12):1658-1663.

7. Hu Y, Davison F, Zhang Z, Xu Q: Endothelial replacement and angiogenesis in arteriosclerotic lesions of allografts are contributed by circulating progenitor cells. Circulation 2003, 108(25):3122-3127.

8. Matsumura M, Fukuda N, Kobayashi N, Umezawa H, Takasaka A, Matsumoto T, Yao EH, Ueno T, Negishi N: Effects of atorvastatin on angiogenesis in hindlimb ischemia and endothelial progenitor cell formation in rats. J Atheroscler Thromb 2009, 16(4):319-326.

9. Lee DY, Cho TJ, Kim JA, Lee HR, Yoo WJ, Chung CY, Choi IH: Mobilization of endothelial progenitor cells in fracture healing and distraction osteogenesis. Bone 2008, 42(5):932-941.

10. Flammer AJ, Gossl M, Widmer RJ, Reriani M, Lennon R, Loeffler D, Shonyo S, Simari RD, Lerman LO, Khosla S, et al: Osteocalcin positive CD133+/CD34-/ $\mathrm{KDR}+$ progenitor cells as an independent marker for unstable atherosclerosis. Eur Heart J 2012, 33(23):2963-2969.

11. Fadini GP, Grego F, Menegolo M, Agostini C, Avogaro A: Arterio-venous gradients of endothelial progenitor cells reveal a complex kinetics in human limb ischemia. Clin Hemorheol Microcirc 2012, 50(4):293-300.

12. Morishita T, Uzui H, Nakano A, Mitsuke Y, Geshi T, Ueda T, Lee JD: Number of endothelial progenitor cells in peripheral artery disease as a marker of severity and association with pentraxin-3, malondialdehyde-modified low-density lipoprotein and membrane type-1 matrix metalloproteinase. J Atheroscler Thromb 2012, 19(2):149-158.

13. Palombo C, Kozakova M, Morizzo C, Gnesi L, Barsotti MC, Spontoni P, Massart F, Salvi P, Balbarini A, Saggese G, et al: Circulating endothelial progenitor cells and large artery structure and function in young subjects with uncomplicated type 1 diabetes. Cardiovasc Diabetol 2011, 10:88.

14. Vasa M, Fichtlscherer S, Aicher A, Adler K, Urbich C, Martin H, Zeiher AM, Dimmeler S: Number and migratory activity of circulating endothelial progenitor cells inversely correlate with risk factors for coronary artery disease. Circ Res 2001, 89(1):E1-E7.

15. Wang HY, Gao PJ, Ji KD, Shen WF, Fan CL, Lu L, Zhu DL: Circulating endothelial progenitor cells, $\mathrm{C}$-reactive protein and severity of coronary stenosis in Chinese patients with coronary artery disease. Hypertens Res 2007, 30(2):133-141.

16. Guven H, Shepherd RM, Bach RG, Capoccia BJ, Link DC: The number of endothelial progenitor cell colonies in the blood is increased in patients with angiographically significant coronary artery disease. J Am Coll Cardiol 2006, 48(8):1579-1587.

17. Ruan C, Shen Y, Chen R, Wang Z, Li J, Jiang Y: Endothelial progenitor cells and atherosclerosis. Front Biosci (Landmark Ed) 2013, 18:1194-1201.

18. Pelliccia F, Pasceri V, Rosano G, Pristipino C, Roncella A, Speciale G, Pannarale G, Schiariti M, Greco C, Gaudio C: Endothelial progenitor cells predict long-term prognosis in patients with stable angina treated with percutaneous coronary intervention. Circ J 2013, 77(7):1728-1735.

19. Glowinska-Olszewska B, Moniuszko M, Hryniewicz A, Jeznach M, Rusak M, Dabrowska M, Luczynski W, Bodzenta-Lukaszyk A, Bossowski A: Relationship between circulating endothelial progenitor cells and endothelial dysfunction in children with type 1 diabetes: a novel paradigm of early atherosclerosis in high-risk young patients. Eur J Endocrinol 2013, 168(2):153-161.

20. Du F, Zhou J, Gong R, Huang X, Pansuria M, Virtue A, Li X, Wang H, Yang XF: Endothelial progenitor cells in atherosclerosis. Front Biosci (Landmark Ed) 2012, 17:2327-2349.

21. Rafat N, Beck G, Pena-Tapia PG, Schmiedek P, Vajkoczy P: Increased levels of circulating endothelial progenitor cells in patients with Moyamoya disease. Stroke 2009, 40(2):432-438.

22. Chu K, Jung KH, Lee ST, Park HK, Sinn DI, Kim JM, Kim DH, Kim JH, Kim SJ, Song EC, et al: Circulating endothelial progenitor cells as a new marker of endothelial dysfunction or repair in acute stroke. Stroke 2008, 39(5):1441-1447. 
23. Pelliccia F, Cianfrocca C, Rosano G, Mercuro G, Speciale G, Pasceri V: Role of endothelial progenitor cells in restenosis and progression of coronary atherosclerosis after percutaneous coronary intervention: a prospective study. JACC Cardiovasc Interv 2010, 3(1):78-86.

24. Guo M, Sahni SK, Sahni A, Francis CW: Fibrinogen regulates the expression of inflammatory chemokines through NF-kappaB activation of endothelial cells. Thromb Haemost 2004, 92(4):858-866.

25. Thacker Rl, Retzinger GS: Adsorbed fibrinogen regulates the behavior of human dendritic cells in a CD18-dependent manner. Exp Mol Pathol 2008, 84(2):122-130.

26. Eidelman RS, Hennekens $\mathrm{CH}$ : Fibrinogen: a predictor of stroke and marker of atherosclerosis. Eur Heart J 2003, 24(6):499-500.

27. Arenillas JF, Alvarez-Sabin J, Molina CA, Chacon P, Montaner J, Rovira A, Ibarra B, Quintana M: C-reactive protein predicts further ischemic events in first-ever transient ischemic attack or stroke patients with intracranial large-artery occlusive disease. Stroke 2003, 34(10):2463-2468.

28. Urbich C, Dimmeler S: Endothelial progenitor cells: characterization and role in vascular biology. Circ Res 2004, 95(4):343-353.

29. Peichev M, Naiyer AJ, Pereira D, Zhu Z, Lane WJ, Williams M, Oz MC, Hicklin DJ, Witte L, Moore MA, et al: Expression of VEGFR-2 and AC133 by circulating human $\mathrm{CD} 34(+)$ cells identifies a population of functional endothelial precursors. Blood 2000, 95(3):952-958.

30. Yoshihara T, Taguchi A, Matsuyama T, Shimizu Y, Kikuchi-Taura A, Soma T, Stern DM, Yoshikawa $H$, Kasahara $Y$, Moriwaki $H$, et al: Increase in circulating CD34-positive cells in patients with angiographic evidence of moyamoya-like vessels. J Cereb Blood Flow Metab 2008, 28(6):1086-1089.

31. Sobrino T, Hurtado O, Moro MA, Rodriguez-Yanez M, Castellanos M, Brea D, Moldes O, Blanco M, Arenillas JF, Leira R, et al: The increase of circulating endothelial progenitor cells after acute ischemic stroke is associated with good outcome. Stroke 2007, 38(10):2759-2764.

32. Liu ZZ, Lv H, Gao F, Liu G, Zheng HG, Zhou YL, Wang YJ, Kang XX: Polymorphism in the human C-reactive protein (CRP) gene, serum concentrations of CRP, and the difference between intracranial and extracranial atherosclerosis. Clin Chim Acta 2008, 389(1-2):40-44.

33. Asahara T, Takahashi T, Masuda H, Kalka C, Chen D, Iwaguro H, Inai Y, Silver M, Isner JM: VEGF contributes to postnatal neovascularization by mobilizing bone marrow-derived endothelial progenitor cells. EMBO J 1999, 18(14):3964-3972.

34. Urbich C, Aicher A, Heeschen C, Dernbach E, Hofmann WK, Zeiher AM, Dimmeler S: Soluble factors released by endothelial progenitor cells promote migration of endothelial cells and cardiac resident progenitor cells. J Mol Cell Cardiol 2005, 39(5):733-742.

doi:10.1186/1471-2377-13-161

Cite this article as: Liu et al:: Higher numbers of circulating endothelial progenitor cells in stroke patients with intracranial arterial stenosis. BMC Neurology 2013 13:161.

\section{Submit your next manuscript to BioMed Central and take full advantage of:}

- Convenient online submission

- Thorough peer review

- No space constraints or color figure charges

- Immediate publication on acceptance

- Inclusion in PubMed, CAS, Scopus and Google Scholar

- Research which is freely available for redistribution 